\title{
Loss of miR-100 enhances migration, invasion, epithelial- mesenchymal transition and stemness properties in prostate cancer cells through targeting Argonaute 2
}

\author{
MIN WANG ${ }^{1}$, DONG REN ${ }^{1}$, WEI GUO ${ }^{1}$, ZEYU WANG $^{1}$, SHUAI HUANG ${ }^{1}$, \\ HONG DU ${ }^{3}$, LIBING SONG ${ }^{2}$ and XINSHENG PENG ${ }^{1}$ \\ ${ }^{1}$ Department of Orthopaedic Surgery/Orthopaedic Research Institute, \\ The First Affiliated Hospital of Sun Yat-sen University, Guangzhou, Guangdong 510080; \\ ${ }^{2}$ State Key Laboratory of Oncology in Southern China/Department of Experimental Research, \\ Sun Yat-sen University Cancer Center, Guangzhou, Guangdong 510060; ${ }^{3}$ Department of Pathology, \\ The First People's Hospital of Guangzhou City, Guangzhou, Guangdong 510180, P.R. China
}

Received February 10, 2014; Accepted April 17, 2014

DOI: $10.3892 /$ ijo.2014.2413

\begin{abstract}
Evidence in literature has demonstrated that some microRNAs (miRNAs) play a pivotal role in most solid tumor metastasis. Previous studies have showed that miR-100 is downregulated in human prostate cancer tissue compared to normal prostate and also significantly decreased in bone metastatic prostate cancer samples compared with primary prostate cancer. Argonaute 2 (AGO2) is the core effector protein of the miRNA-induced silencing complex and overexpression of $\mathrm{AGO} 2$ might enhance tumor metastasis. However, it is unknown whether and how miR-100 and AGO2 regulates metastasis of prostate cancer. Here, we report that miR-100 negatively regulated migration, invasion, epithelialmesenchymal transition (EMT), colony formation, spheroid formation and expression of the stemness factors c-Myc, Oct4 and Klf4 in PC-3 and DU145 cells. Furthermore, miR-100 expression was negatively correlated with bone metastasis of prostate cancer patients. Notably, luciferase assay showed that AGO2 was a direct target of miR-100. Downregulation of AGO2 repressed migration, invasion, EMT and stemness of prostate cancer cells, and reversed the effects seen with miR-100 downregulation. Downregulation of AGO2 enhanced
\end{abstract}

Correspondence to: Professor Xinsheng Peng, Department of Orthopaedic Surgery, The First Affiliated Hospital of Sun Yat-sen University, 58 Zhongshan 2rd Road, Guangzhou, Guangdong 510080, P.R. China

E-mail: pengxs66@yahoo.com

Abbreviations: PCa, prostate cancer; miRNAs, microRNAs; EMT, epithelial-mesenchymal transition; CSCs, cancer stem cells; Ago2, Argonaute 2; RISC, RNA-induced silencing complex

Key words: prostate cancer, Argonaute 2, microRNAs, epithelialmesenchymal transition, cancer cell stemness, bone metastasis expression of miR-34a and miR-125b which can suppress migration, invasion, EMT and stemness of cancer cells. Taken together, our findings indicate that loss of miR-100 promotes the metastatic ability of prostate cancer cells at least partially by upregulating AGO2 expression through modulating migration, invasion, EMT and stemness of cancer cells, and suggest that miR-100/AGO2 may play an important role in regulating the metastasis of prostate cancer and is a potential target of prevention and therapy.

\section{Introduction}

Prostate cancer $(\mathrm{PCa})$ is the most frequently diagnosed malignant tumor in male and the second leading cause of cancer deaths in Western countries (1). The main problem arising from $\mathrm{PCa}$ is its propensity to metastasize to bone and raise bone relative events and death (2). Thus it is very important to understand the mechanism of metastasis progression for preventing and developing anti-metastatic therapies.

Substantial evidence has demonstrated that some microRNAs (miRNAs), which is a class of small non-coding regulatory RNAs (19-25 nucleotides), play a pivotal role in most solid tumor metastasis $(3,4)$. In PCa, a series of miRNAs have been identified as suppressors of metastasis, such as miR-145, -143, -205, -34a, -203 and -200c (5-9). Recently, several studies also found that miR-100 expression is downregulated in human PCa tumor tissue compared to normal prostate (10-12). Importantly, miR-100 level significantly decreases in the bone metastasis PCa samples compared with primary $\mathrm{PCa}(5)$. Moreover, it is also downregulated during the PCa progression $(10,13,14)$ and its downregulation is related with hormone-refractory PCa (15). However, the importance of miR-100 in bone metastasis of PCa has not been elucidated to date.

Epithelial-mesenchymal transition (EMT) plays a key role in tumor cell metastasis (16) and also has been identified as an important step in bone metastasis of PCa $(2,17)$. Furthermore, E-cadherin-mediated cell-adhesion system plays a critical role 
in EMT which is regulated by various EMT-inducing transcription factors including Snail1/2, Twist1/2 and Zeb1/2 (18). Emerging evidence has demonstrated that cancer stem cells (CSCs) also are the critical drivers of tumor progression and metastasis (19). Importantly, certain miRNAs directly regulated EMT and the characteristics of CSCs $(3,20,21)$. However, it is not known whether and how miR-100 regulates EMT and the characteristics of CSCs.

The bioinformatics (TargetScan) predicts that Argonaute 2 (AGO2 or Eif2c2) may be a putative target of miR-100. AGO2 is the core effector proteins of the miRNA-induced silencing complex (miRISC) (22) and plays a role in short interfering RNA-mediated gene silencing (23). Furthermore, AGO2 also is as a pivotal factor in some miRNA biosynthesis (24) and maturation (25). Notably, Ago2 was overexpressed in some malignant tumors, including PCa $(24,26,27)$ and silencing of $\mathrm{AGO} 2$ arrested growth and promoted apoptosis of some malignant tumor cells $(25,28)$. More importantly, overexpression of Ago2 promotes hepatocellular carcinoma (HCC) tumorigenesis and metastasis (23). Downregulation of AGO2 also retarded self-renewal in embryonic stem cells (29) and colony formation of HCC cells (23). These findings suggest that overexpression of $\mathrm{AGO} 2$ might enhance tumor metastasis. However, it is unknown whether and how AGO2 is involved in bone metastasis of PCa. Thus, we hypothesize that miR-100 directly targets AGO2 through which miR-100 negatively regulates metastatic abilities of PCa cells by modulating migration, invasion, EMT and stemness properties of cancer cells.

\section{Materials and methods}

Cell culture and generation of stable transfected cell lines. The PC-3 cell line and DU145 cell line of PCa were purchased from American Type Culture Collection (ATCC). The cells were grown in Ham's F-12 culture medium (Hyclone) and DMEM culture medium (Hyclone), respectively, supplemented with $10 \%$ fetal bovine serum (Hyclone). Cells were grown in a humidified atmosphere of $5 \% \mathrm{CO}_{2}$ at $37^{\circ} \mathrm{C}$. The sequence of pri-miR-100, anti-miR-100 and si-h-RNA-AGO2 (a small hairpin RNA targeting AGO2, 5'-CACGGAAGUCCAUCUGAA dTdT-3') were cloned into pMSCV-puromycin plasmid. Then, the plasmids were transfected into 293FT cells which were used as virus-generating host cells by calcium phosphate precipitation as described previously (30). After incubation at $37^{\circ} \mathrm{C}$ for $6 \mathrm{~h}$ after transfection, the media were changed and the cells were incubated overnight. To produce new viruses, the media were collected three times a day until 293FT cells reached total confluence. Media containing viruses were used to infect PC-3 cells and DU145 cells. Twenty-four hours after the addition of viruses, infected cells were selected by adding puromycin to the growth medium. Stable cell lines were verified by qRT-PCR.

Plasmids, virus production and infection of target cells. The different regions of human miR-100 promoter were generated by PCR amplification from PC-3 cells and cloned into the KpnI/HindIII sites of the pGL3-basic-luciferase reporter plasmid, respectively (Promega, Madison, WI, USA). The full length AGO2-3'-UTR region was generated by PCR amplifica- tion from DNA of PC-3 cells, and subcloned into pEGFP-C3 and a modified pGL3-control-luciferase vector. To silence endogenous AGO2 expression, RNAi oligonucleotides were synthesizes by Invitrogen and cloned into the pSuper-retropuro plasmid (Oligoengine, WA, USA). The sequences of the sense strand for AGO2 was 5'-CACGGAAGUCCAUCUGAA dTdT-3'. The miR-100 mimic and miR-100 inhibitor were purchased from RiboBio (RiboBio Co., Ltd., Guangzhou, Guangdong, China). Transient transfection was performed using the Lipofectamine 2000 reagent (Invitrogen) according to the manufacturer's instructions.

Tissue samples and RNA extraction. Tissue samples were collected from 64 primary PCa patients. The methods of data collection and RNA extraction were as previously described (5). The Institutional Ethics Board (IRB) at The First Affiliated Hospital of Sun Yat-sen University approved the study.

Luciferase assay. Luciferase assays were carried out in 293FT cells. Cells were co-transfected with miRNAs and luciferase reporter plasmids in 6-well plates and cultured for $48 \mathrm{~h}$ before the cells were harvested and lysed for luminescence detection. The following procedure and detection were performed using a luciferase assay kit (Promega) according to the manufacturer's protocol. Renilla luciferase was activated to emitting the primary luminescence, and firefly luminescence was used for normalization. Each test was repeated in triplicate.

Quantitative reverse transcription-PCR. The procedure was performed according to the manual of All-in-One ${ }^{\mathrm{TM}}$ miRNA qRT-PCR Detection kit (GeneCopoeia, USA). Total RNAs were extracted from cultured cells by using RNeasy kit (Qiagen), and were reverse transcribed by adding poly-A sequence, and real-time PCR analysis was performed with specific primer to hsa-miRNAs which need to be checked (GeneCopoeia). Each sample was analyzed in triplicate. No template and no reverse transcription were included as negative controls. U6 snRNA was used as normalization control. Relative expression levels from three independent experiments were calculated following the $2^{-\Delta \Delta \mathrm{Ct}}$ method of Livak and Schmittgen (31).

Western blotting. For the analysis of expression of related proteins, western blot assay was carried out. Equal amounts of proteins from the supernatant were loaded per lane and resolved by SDS-polyacrylamide electrophoresis. Then, the proteins was transferred onto PVDF membrane (Millipore), blocked by $5 \%$ non-fat milk for $1 \mathrm{~h}$ at room temperature, and probed with probed with primary antibodies $(1: 1,000)$ overnight at $4^{\circ} \mathrm{C}$, including mouse anti-AGO2 (Abcam); anti-ZEB1 (Sigma, USA); rabbit anti-Oct4, c-Myc, Klf4, CD44 and mouse anti-E-cadherin, vimentin (CST, Cell Signaling Technology); mouse anti-fibronectin, $\mathrm{N}$-cadherin (BD Biosciences). Membranes were washed thrice (10 min each) in TBS-T buffer and incubated for $40 \mathrm{~min}$ at room temperature with horseradish peroxidase-conjugated anti-mouse or anti-rabbit secondary antibodies. Membranes were washed thrice (10 min each) in TBS-T and developed using the ECL system. Protein loading was normalized by reprobing the blots with rabbit anti- $\beta$-actin (CST, Cell Signaling Technology). 
A

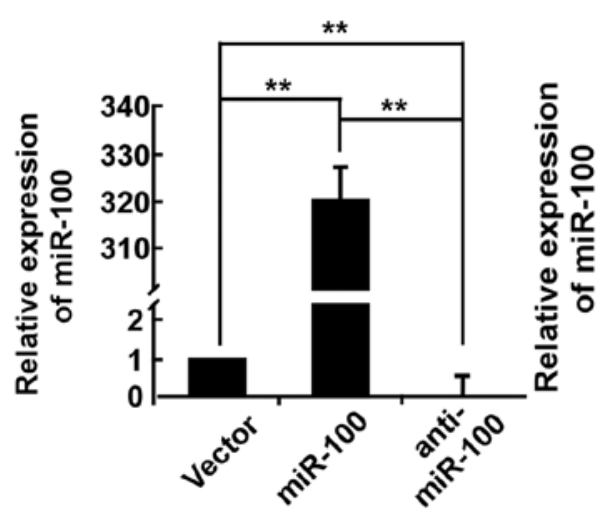

C

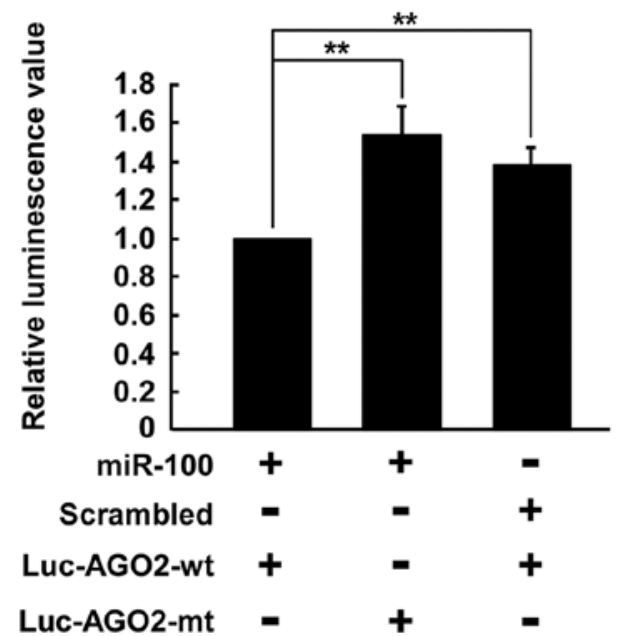

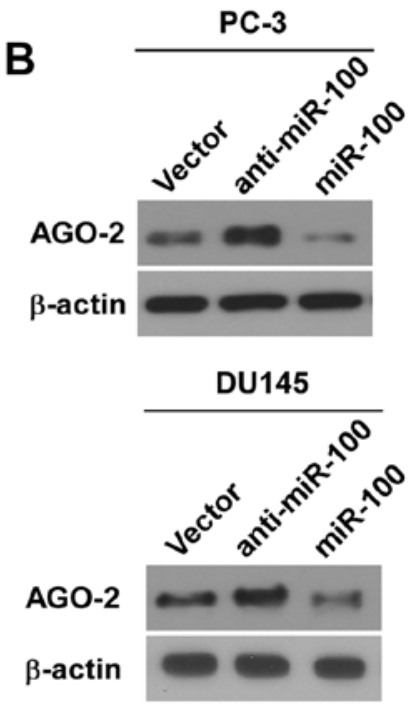

D

Figure 1. miR-100 negatively regulates expression of AGO2 by directly binding to its 3'-UTR. (A) miR-100 expression was detected by real-time PCR. (B) AGO2 expression was detected by western blotting. (C) Relative luminescence transfected with different factors in luciferase assay are presented as the mean \pm SEM of each group ( ${ }^{* *}$ p<0.01). (D) Wild-type 3'-UTR sequence or mutant 3'-UTR sequence of AGO2 was cloned into luciferase plasmids (Luc-AGO2-wt or Luc-AGO2-mt, respectively).

Wound healing assay. PCa cells were trypsinized and seeded into 6-well culture plates $24 \mathrm{~h}$ before scratching and grew to reach almost total confluence in $24 \mathrm{~h}$, followed by non-serum starvation for $24 \mathrm{~h}$. After cell monolayers formed, an artificial homogeneous wound was scratched onto the monolayer with a sterile tip (Axygen, USA). After scratching, the cells were washed with PBS and cultured in $10 \%$ fetal bovine serum media. Images of PC-3 cells migrating into the wound were captured at time-points 0,6 and $12 \mathrm{~h}$ by inverted microscope (x40).

Invasion assay. Invasion assay was conducted by using Transwell chamber consisting of 8-mm membrane filter inserts (Corning) coated with Matrigel (BD Biosciences). Briefly, the cells were trypsinized and suspended in serum-free medium. Then, $1.5 \times 10^{5}$ cells were added to the upper chamber, but lower chamber was filled with $1 \mathrm{ml}$ medium with $10 \%$ FBS. After incubation for 24-48 h, cells passed through the coated membrane to the lower surface, in which cells were fixed, stained, photographed, and quantified by counting them in five random high power fields (x100).

Colony formation assay. The cells were trypsinized as single cells and suspended in $10 \%$ fetal bovine serum medium. Cells
(300 cells) were seeded into each well of 6-well plates for 10-14 days, and colonies were dyed with crystal violet. Plating efficiency $=$ number of colonies $(\geq 50$ cells per colony $) /$ per input cells $\mathrm{x} 100 \%$. To determine the morphology of the different colonies they were observed under a light microscope.

Self-renewing spheroid formation assay. Cells (500 cells/well) were seeded into 6-well Ultra Low Cluster plate (Corning) and were cultured in suspension in serum-free DMEM-F12 (BioWhittaker), supplemented with B27 (1:50, Invitrogen), $20 \mathrm{ng} / \mathrm{ml}$ EGF (BD Biosciences), 0.4\% bovine serum albumin (Sigma), and $4 \mathrm{mg} / \mathrm{ml}$ insulin (Sigma) for 10-12 days. After 10-12 days, the number of PC-3 cell spheres (tight, spherical, non-adherent masses $>50 \mu \mathrm{m}$ in diameter) were counted, and images of the spheres were scored under an inverse microscope. Sphere formation efficiency $=$ colonies $/$ input cells $\mathrm{x} 100 \%$.

Statistical analyses. All statistical analyses were carried out using the SPSS 17.0 statistical software package. Means \pm SD was calculated and two-tailed Student's t-test or one-way ANOVA was performed using the data analysis tools provided by the software. The correlation coefficient (Spearman rank correlation test) was calculated to estimate the linear corre- 

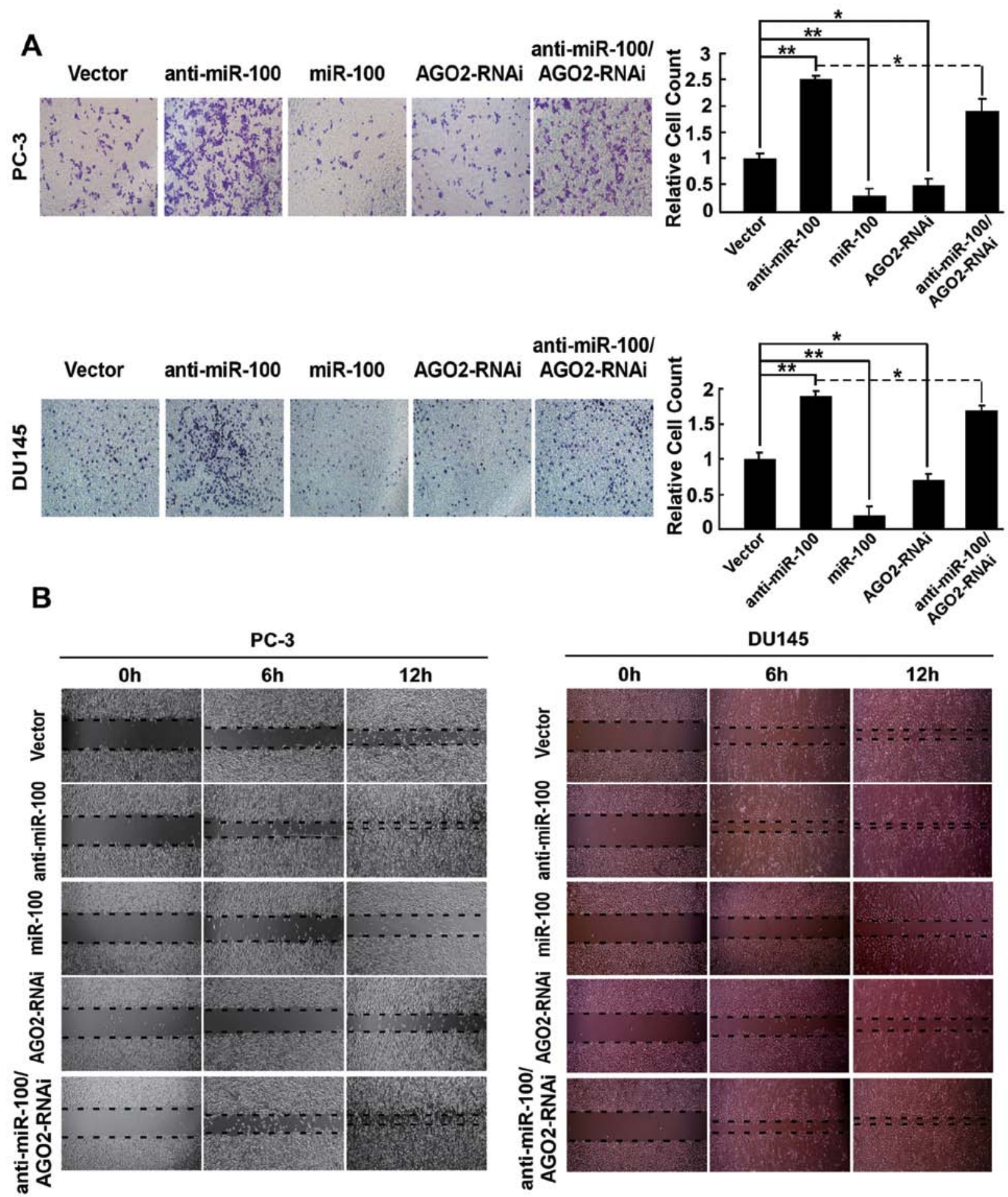

Figure 2. miR-100/AGO2 regulates migration and invasion of PCa cells. (A) miR-100 negatively regulated invasion, and downregulated AGO2 repressed invasion and reversed the effects of the downregulation of miR-100 on promoting invasion of PC-3 and DU145 cells. (B) miR-100 negatively regulated migration, and downregulated AGO2 repressed migration and reversed the effects of downregulation of miR-100 on promoting migration of PC-3 and DU145 cells $\left(* \mathrm{p}<0.05,{ }^{* *} \mathrm{p}<0.01\right)$.

lation between miR-100 and the clinicopathology in the specimens. $\mathrm{p}<0.05$ was considered statistically significant.

\section{Results}

MiR-100 directly targets AGO2 through interacting with the 3 '-UTR. Since miRNAs regulate gene expression by sequencespecific binding to the 3'-UTR of targeted mRNA and the analysis using publicly available algorithms (TargetScan, miRanda) indicated that the AGO2-3'-UTR region is the theoretical conserved target of miR-100, we examined whether miR-100 may directly target the AGO2-3'-UTR. Western blotting revealed that the expression level of AGO2 was significantly decreased in cells infected with miR-100 and increased in cells transfected with miR-100 inhibitor (Fig. 1A and B), suggesting that miR-100 may degrade the mRNA of 
A

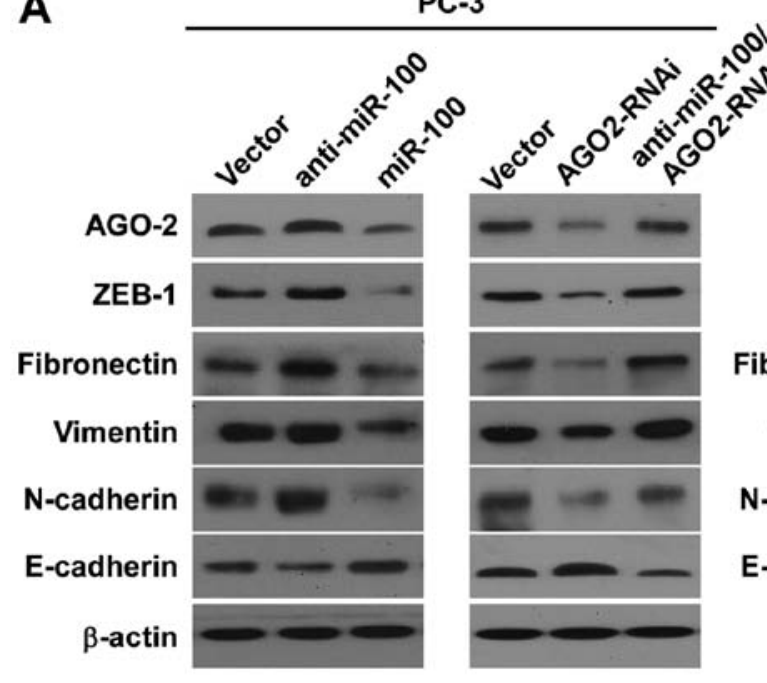

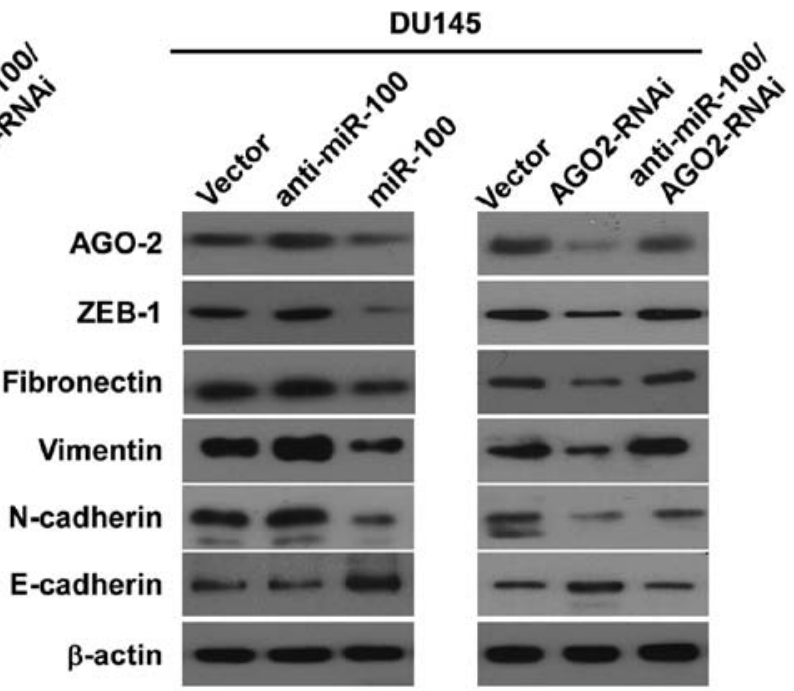

B

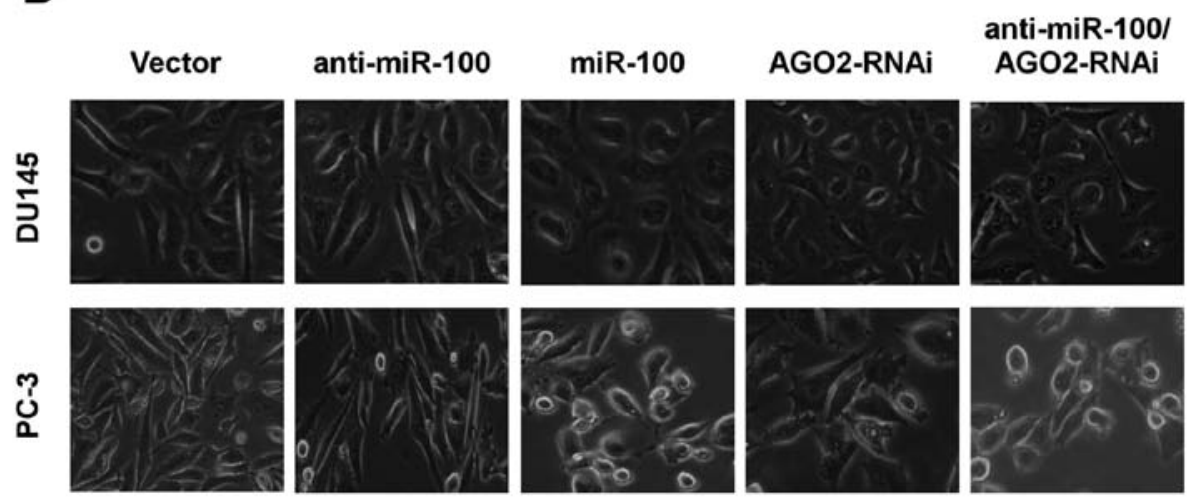

Figure 3. miR-100/AGO2 regulate EMT of PCa cells. (A) miR-100 positively regulated E-cadherin expression and negatively regulated N-cadherin, fibronectin, vimentin and ZEB1 expression; downregulated AGO2 increased E-cadherin expression and suppressed N-cadherin, fibronectin, vimentin and ZEB1 expression; downregulation of AGO2 reversed the effects of downregulation of miR-100 on repressing E-cadherin expression and promoting N-cadherin, fibronectin, vimentin and ZEB1 expression in PC-3 and DU145 cells. (B) Upregulation of miR-100 and downregulation of AGO2 converted the stick-like or long spindle-shaped mesenchymal profile to a cobblestone-like or a short spindle-shaped epithelial morphology, and downregulation of AGO2 reversed the effects of downregulation of miR-100 on cell morphological changes in PC-3 and DU145 cells.

AGO2. We carried out a dual-luciferase reporter gene assay. Luciferase reporter plasmids containing the wild-type 3'-UTR (Luc-AGO2-wt) or mutant 3'-UTR (Luc-AGO2-mt) of AGO2 (Fig. 1D) were constructed to determine the targeted region. As shown in Fig. 1C, luciferase activities were significantly higher in cells transfected with either Luc-AGO2-mt or scrambled miRNA, with 1.54- and 1.39-fold higher levels, respectively, than that in cells transfected with Luc-AGO2-wt. Moreover, the scrambled miRNA base sequence did not suppress Luc-AGO2-wt, and miR-100 could not bind to the mutant AGO2-3'-UTR. Thus, these observations indicated that miR-100 directly targeted AGO2 through interacting with the 3'-UTR.

MiR-100 negatively regulates migration, invasion and EMT in PCa cells. To investigate the role of miR-100 in the development and progression of $\mathrm{PCa}$ metastasis, overexpressing miR-100 (PC-3/miR-100 and DU145/miR-100) and downexpressing miR-100 (PC-3/anti-miR-100 and DU145/ anti-miR-100) cell lines were established by retrovirus transfection. Blank plasmid transfected cells (PC-3/vector and
DU145/vector) were used as the control group. The expression levels of miR-100 in all cell lines were confirmed by real-time PCR (Fig. 1A). By using wound healing assay to assess cell migration and trans-well Matrigel invasion assay to assess the invasive ability of cells, we found that the invasive ability of PC-3/miR-100 and DU145/miR-100 and the healing speed of the cell wound were repressed, and inversely, the invasive ability and the healing speed of the cell wound of PC-3/antimiR-100 DU145/anti-miR-100 were promoted compared to PC-3/vector and DU145/vector (Fig. 2).

To investigate whether miR-100 inhibited invasiveness by repressing EMT, we examined the influence of miR-100 on expressions of E-cadherin, $\mathrm{N}$-cadherin, fibronectin, vimentin and ZEB1 in all cell lines by western blotting. We found that E-cadherin expression increased in PC-3/miR-100 and DU145/ miR-100, and decreased in PC-3/anti-miR-100 and DU145/ anti-miR-100 compared with PC-3/vector and DU145/vector. Contrarily, N-cadherin, fibronectin, vimentin and ZEB1 expressions decreased in PC-3/miR-100 and DU145/miR-100, and increased in PC-3/anti-miR-100 and DU145/anti-miR-100 (Fig. 3A). We then examined the change of morphology of 

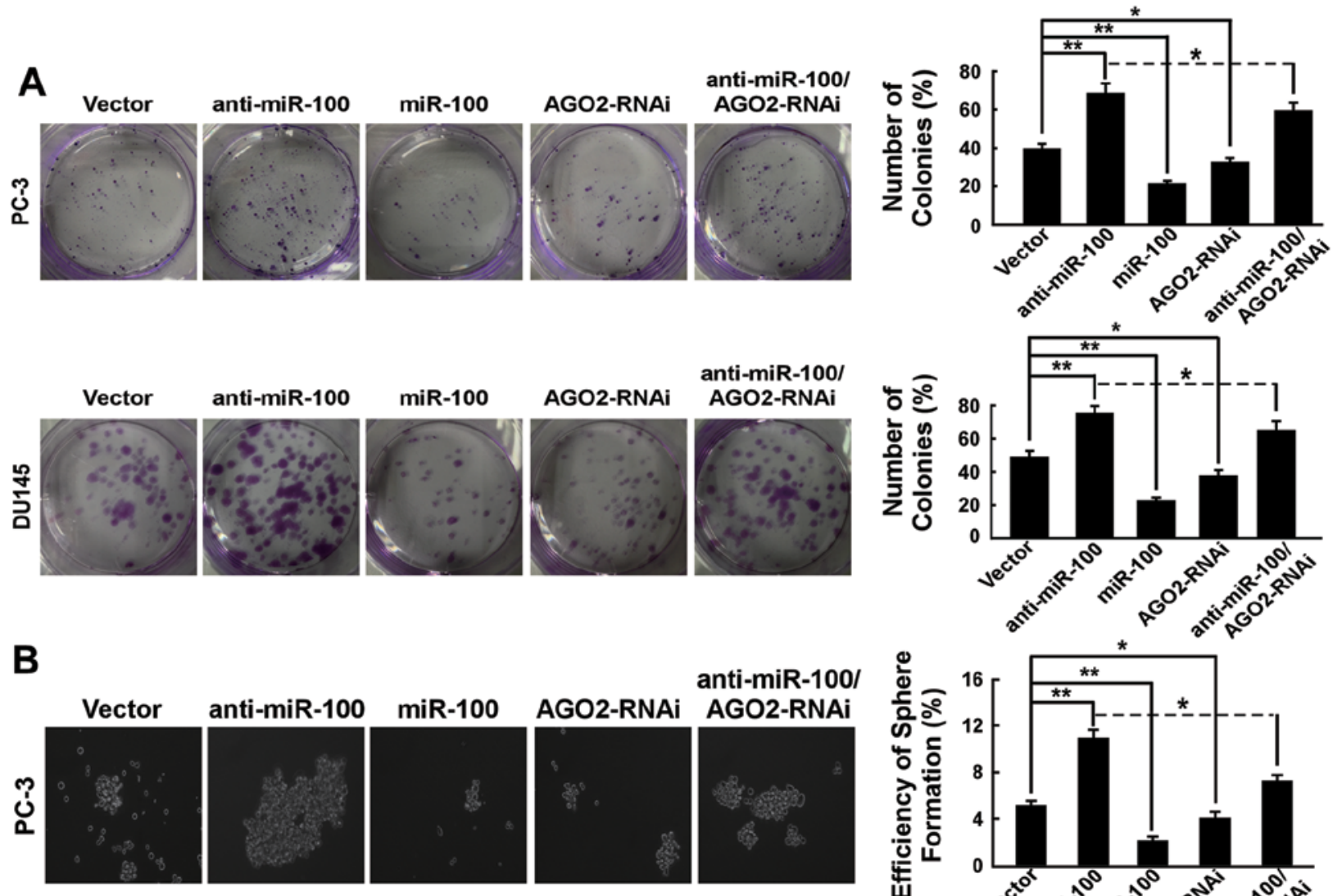

anti-miR-100/
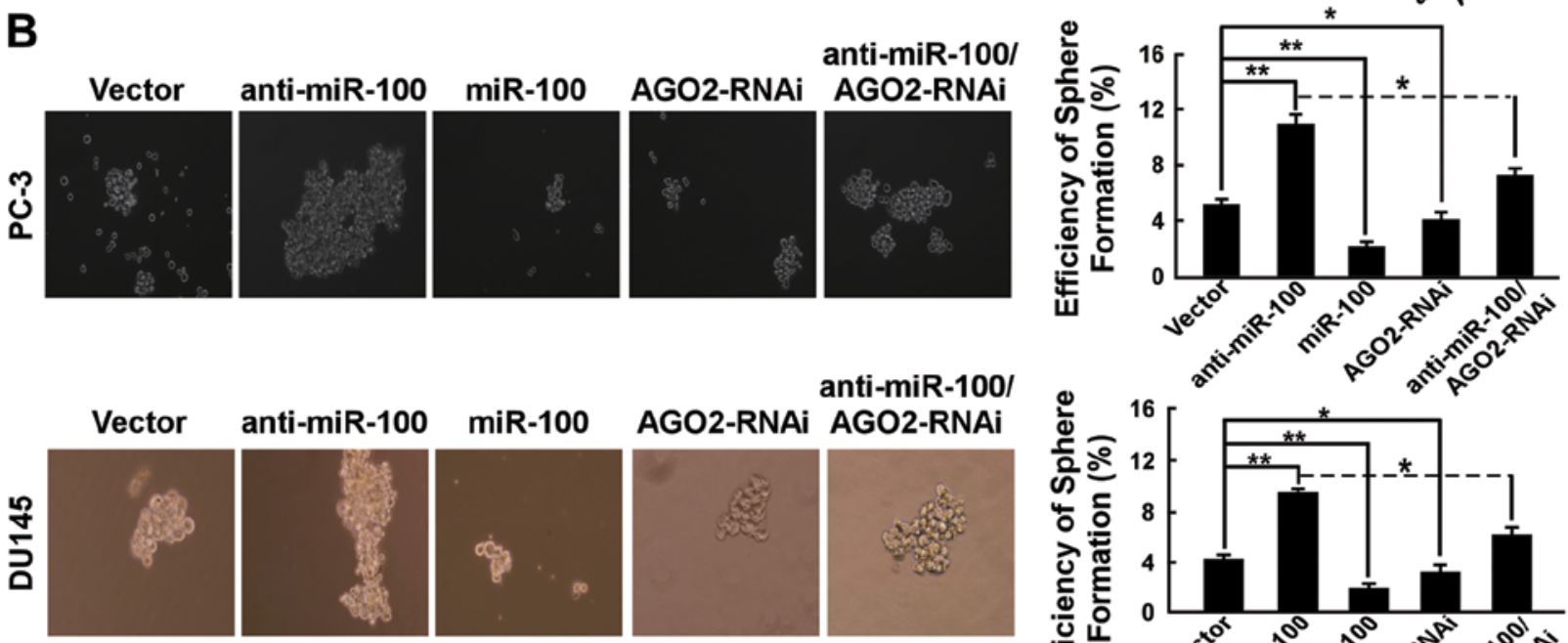

C

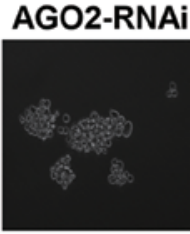

anti-miR-100/
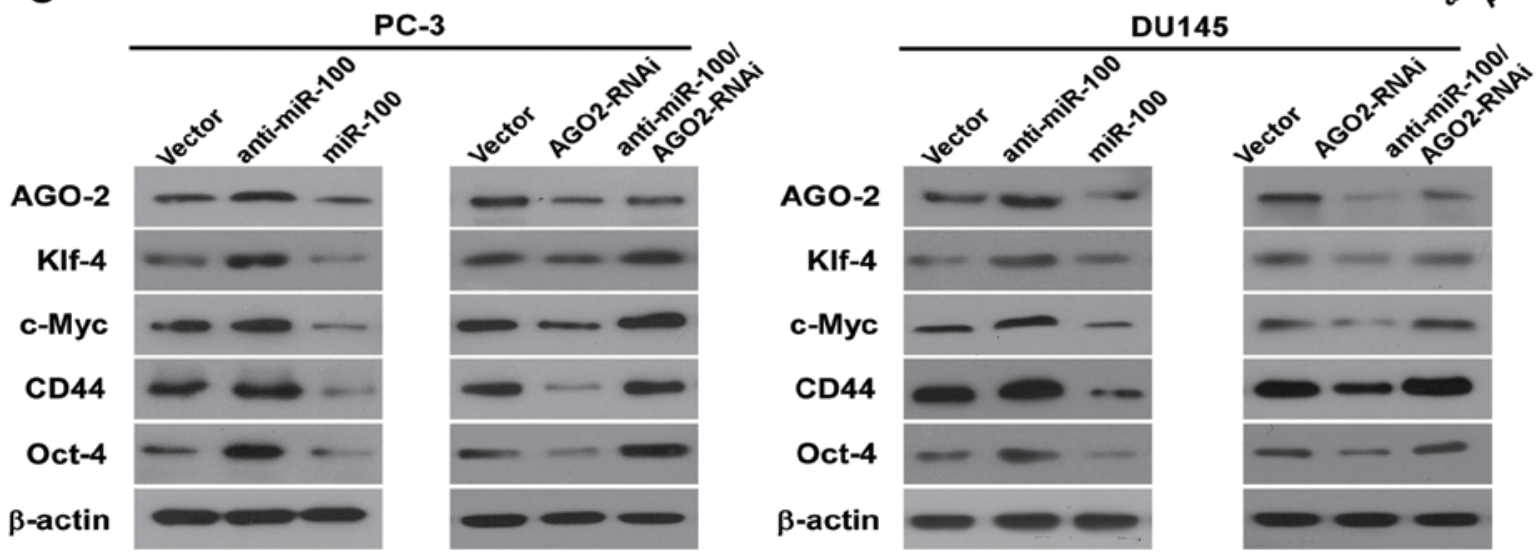

Figure 4. miR-100/AGO2 regulate stemness of PCa cells. (A) miR-100 negatively regulated colony formation, and downregulation of AGO2 repressed colony formation and reversed the effects of downregulation of miR-100 on promoting colony formation of PC-3 and DU145 cells. (B) miR-100 negatively regulated spheroid formation and downregulation of $\mathrm{AGO} 2$ repressed spheroid formation and reversed the effects of downregulation of miR-100 on spheroid formation of PC-3 and DU145 cells. (C) miR-100 negatively regulated CD44, C-Myc, Oct4 and Klf4 expression and downregulation of AGO2 repressed CD44, C-Myc, Oct4 and Klf4 expression and reversed the effects of downregulated miR-100 on promoting CD44, C-Myc, Oct4 and Klf4 expres$\operatorname{sion}\left({ }^{*} \mathrm{p}<0.05,{ }^{* *} \mathrm{p}<0.01\right)$.

all cell lines with specific reference to special characteristics during EMT. The results showed that overexpressing
miR-100 in PC-3 and DU145 cells converted the predominant mechenchymal phenotype to an evident epithelial phenotype 
Table I. The clinical data of prostate cancer patients.

No.of cases $(\%)$

Age (years)
$\leq 75$
$>75$

Total PSA

$\begin{array}{ll}\leq 85.5 & 32(50.0) \\ >85.5 & 32(50.0)\end{array}$

Free PSA

$\begin{array}{ll}\leq 5 & 33(51.6) \\ >5 & 31(48.4)\end{array}$

Gleason score

$\begin{array}{ll}\leq 7 & 31(48.4) \\ >7 & 33(51.6)\end{array}$

Bone metastasis

Yes

No

i.e., from the stick-like or long spindle-shaped mesenchymal profile to a cobblestone-like or a short spindle-shaped epithelial morphology and downregulation of miR-100 in PC-3 and DU145 cells increased the long spindle-shaped mesenchymal profile (Fig. 3B).

MiR-100 negatively regulates colony formation, tumor spheroid formation, CSC marker CD44 and 'stemness' factor expression in PCa cells. To determine the efficiency of miR-100 in regulating the stemness of PC-3 and DU145 cells, the colony-forming and spheroid formation assay were performed. In the colony-forming assay, we found that the number of colonies (\% plating efficiency) were $22 \%$ in $\mathrm{PC}-3 /$ miR-100, 69\% in PC-3/anti-miR-100\%, compared with $40 \%$ in PC-3/vector, and $23 \%$ in DU145/miR-100, $75 \%$ in DU145/ anti-miR-100, compared with 49\% in DU145/vector (Fig. 4A). These results indicated a dramatically repressing ability of miR-100 on colony formation. In spheroid formation assay, there were prostaspheres in all kinds of cells after culturing for 12 days under non-adherent conditions. As shown in Fig. 4B, the spheroid formation efficiency was $2.2 \%$ in PC-3/ miR-100, 11\% in PC-3/anti-miR-100, compared with $5.2 \%$ in PC-3/vector, and 1.9\% in DU145/miR-100, 9.6\% in DU145/ anti-miR-100, and compared with $4.3 \%$ in DU145/vector.

To determine whether miR-100 also has an influence on CSC marker and stemness factor expression in PC-3 and DU145 cells, we detected the expression of stem cell properties-associated factor and marker including CD44, c-Myc, Oct4, and Klf4. As shown in Fig. 4C, compared with vector, overexpression of miR-100 in PC-3 and DU145 cells reduced the expression of $\mathrm{CD} 44$, which has been described as a prostate CSC marker based on clinical investigations and in vitro studies of PCa cell lines, and downregulated the expression of Oct4, c-Myc and Klf4, which are the key stemness factors, and are required for maintaining self-renewal and pluripotency of stem cells. Downregulation of miR-100 in PC-3 and DU145 cells upregulated the expression of CD44, Oct4, c-Myc and Klf4.

MiR-100 is negatively correlated with bone metastasis, the Gleason score and serum PSA level in primary PCa. To determine whether the expression of miR-100 was related to clinicopathology in primary PCa patients, we collected 64 clinical paraffin-fixed PCa samples (the clinical data are showed in Table I). We detected expression level of miR-100 by using qRT-PCR. By comparing the mir-100 level of PCa specimens in 36 patients with bone metastasis with that in 28 patients without bone metastasis, we found that the mir-100 level in PCa specimens with bone metastases was significantly lower than that in PCa specimens without metastases (Fig. 5A). Next we assessed whether the mir-100 level was related with Gleason score, serum-free PSA and total PSA in primary PCa. The results showed significant inverse correlation between expression of miR-100 and Gleason score (Fig. 5C), the level of serum-free PSA (Fig. 5B) and the level of total PSA (Fig. 5D).

Downregulation of $A G O 2$ represses invasion, migration and EMT of PCa cells. To demonstrate the effect of AGO2 on the development and progression of PCa metastasis, AGO2-downregulated cell lines were established in PC-3 cells (PC-3/AGO2-RNAi) and DU145 cells (DU145/AGO2RNAi). The expression level of AGO2 was confirmed by western blotting (Fig. 3A). Transwell-Matrigel was used to assess the invasive ability of cells. We found that downregulating AGO2 decreased the invasive ability to $27.5 \%$ of PC-3/ vector and $22.6 \%$ of DU145/vector (Fig. 2A). As shown in Fig. 2B, cell migration was observed by wound healing assay and the healing speed of the cell wound decreased in PC-3/ AGO2-RNAi and DU145/AGO2-RNAi compared with PC-3/ vector and DU145/vector (Fig. 3).

We then investigated whether $\mathrm{AGO} 2$ could regulate invasion and migration by repressing EMT. We examined the influence of downregulation of $\mathrm{AGO} 2$ on expression of E-cadherin, $\mathrm{N}$-cadherin, fibronectin, vimentin and ZEB1 in PC-3 and DU145 cells by western blotting, and found that E-cadherin increased in PC-3/AGO2-RNAi and DU145/AGO2-RNAi, and $\mathrm{N}$-cadherin, fibronectin, vimentin and ZEB1 decreased in PC-3/AGO2-RNAi and DU145/AGO2-RNAi compared with vector control cells (Fig. 3A). We also examined the change of morphology of PC-3 cells and DU145. The results showed that PC-3/AGO2-RNAi and DU145/AGO2-RNAi converted the predominant mechenchymal phenotype to an evident epithelial phenotype i.e., from the stick-like or long spindleshaped mesenchymal profiles to a short spindle-shaped or a cobblestone-like epithelial morphology (Fig. 3B).

Downregulation of AGO2 inhibits colony formation, tumor spheroid formation, CSC marker CD44 and stemness factor expression in PCa cells. To demonstrate the effect of AGO2 on regulating stemness of PC-3 and DU145 cells, the colony formation and sphere formation assays were performed. In the colony-forming assay, we found that the number of colonies (\% plating efficiency) was 33\% in PC-3/AGO2-RNAi compared with $40 \%$ in PC-3/vector and $38 \%$ in DU145/AGO2-RNAi compared with $49 \%$ in DU145/vector (Fig. 4A). In the sphere 

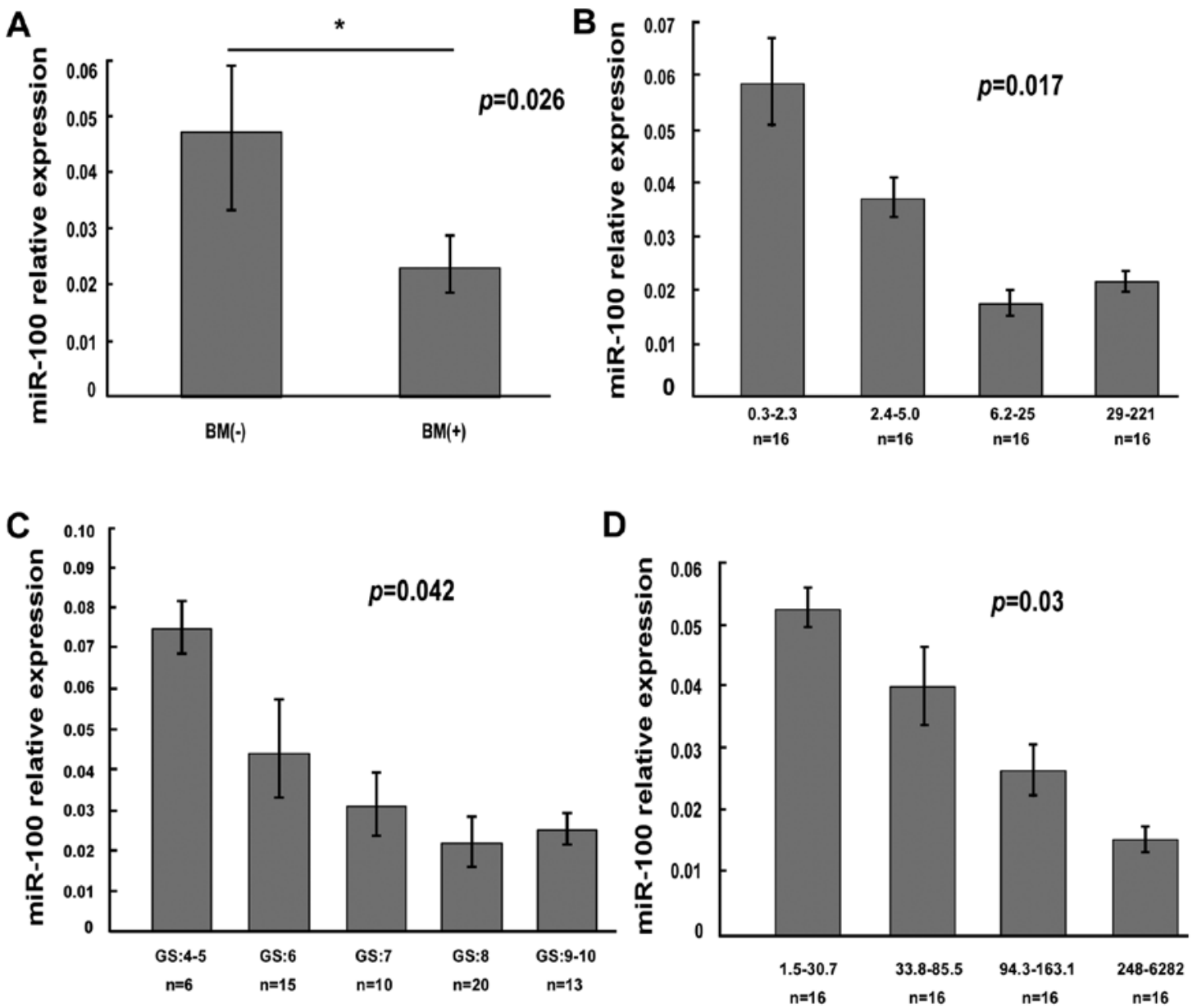

Figure 5. Downregulation of miRs-100 is associated with clinicopathological features of primary PCa. (A) The expression of miRs-100 in the patients with bone metastases was significantly lower than that without metastases (t-test, $\mathrm{p}=0.026$ ). (C) miR-100 expression was negatively correlated with the Gleason scores (Spearman correlation -0.255; $\mathrm{p}=0.042$ ). (B and $\mathrm{D}$ ) Tumor samples were divided into four groups with equal sample size. miR-100 expression was negatively correlated with the level of free and total PSA of serum (Spearman correlation $-0.298, \mathrm{p}=0.017$; Spearman correlation -0.371 , $\mathrm{p}=0.003$, respectively).

formation assay, there were prostaspheres in all the cell types after culturing for 12 days under non-adherent conditions. As shown in Fig. 4B, the spheroid formation efficiency was $4.1 \%$ in PC-3/AGO2-RNAi and $3.2 \%$ in DU145/AGO2-RNAi. Compared to vector (5.2\% in PC-3, $4.3 \%$ in DU145), downregulation of $\mathrm{AGO} 2$ significantly decreased the proportion of self-renewal in PC-3 and DU145 cells.

Further, to demonstrate whether downregulation of AGO2 also has an impact on stemness factors of PCa cells, we measured the expression of CD44, c-Myc, Oct4, Klf4 and Sox2. As shown in Fig. 4C, PC-3/AGO2-RNAi and DU145/ AGO2-RNAi reduced the expression of CD44, Oct4, c-Myc and Klf4 compared to vectors. These data indicate that downregulating $\mathrm{AGO} 2$ repressed stemness of $\mathrm{PCa}$ cells.

Downregulation of AGO2 reverses the effects of downregulated miR-100 promoting migration, invasion, EMT and stemness in PCa cells. Because AGO2 is directly regulated by miR-100, we determined whether AGO2 can reverse the effects of miR-100 on migration, invasion, EMT and stemness in PCa cells. AGO2 expression was downregulated by sequence AGO2-shRNA in PC-3/anti-miR-100. The expres- sion of AGO2 was confirmed by real-time PCR and western blotting. We found that downregulation of AGO2 partially reversed the effects of miR-100 downregulation in migration speed and invasive ability in PC-3 and DU145 cells (Fig. 2). AGO2 downregulation also partially counteracted the effects of miR-100 downregulation of the expression of E-cadherin, $\mathrm{N}$-cadherin, fibronectin, vimentin and ZEB1 and cell morphology (Fig. 3). As shown in Fig. 4, AGO2 downregulation in part counteracted effects of miR-100 downregulation on colony-forming capability, spheroid formation efficiency and the stemness factors expression in PC-3 and DU145 cells. These data indicate that inhibition of $\mathrm{AGO} 2$ at least to some extent reversed the effects of miR-100 downregulation on migration, invasion, EMT and stemness in PCa cells.

Downregulation of AGO2 promotes miR-125b and miR34a expression in PCa cells. Previous studies showed that Ago2 directly regulated certain miRNA biosynthesis (24) and maturation (25). We attempted to determine whether Ago2 promoted the metastatic ability of PCs cells by regulating miRNA expression. We evaluated the expression levels of 17 miRNAs, which were reported to play a role in development 

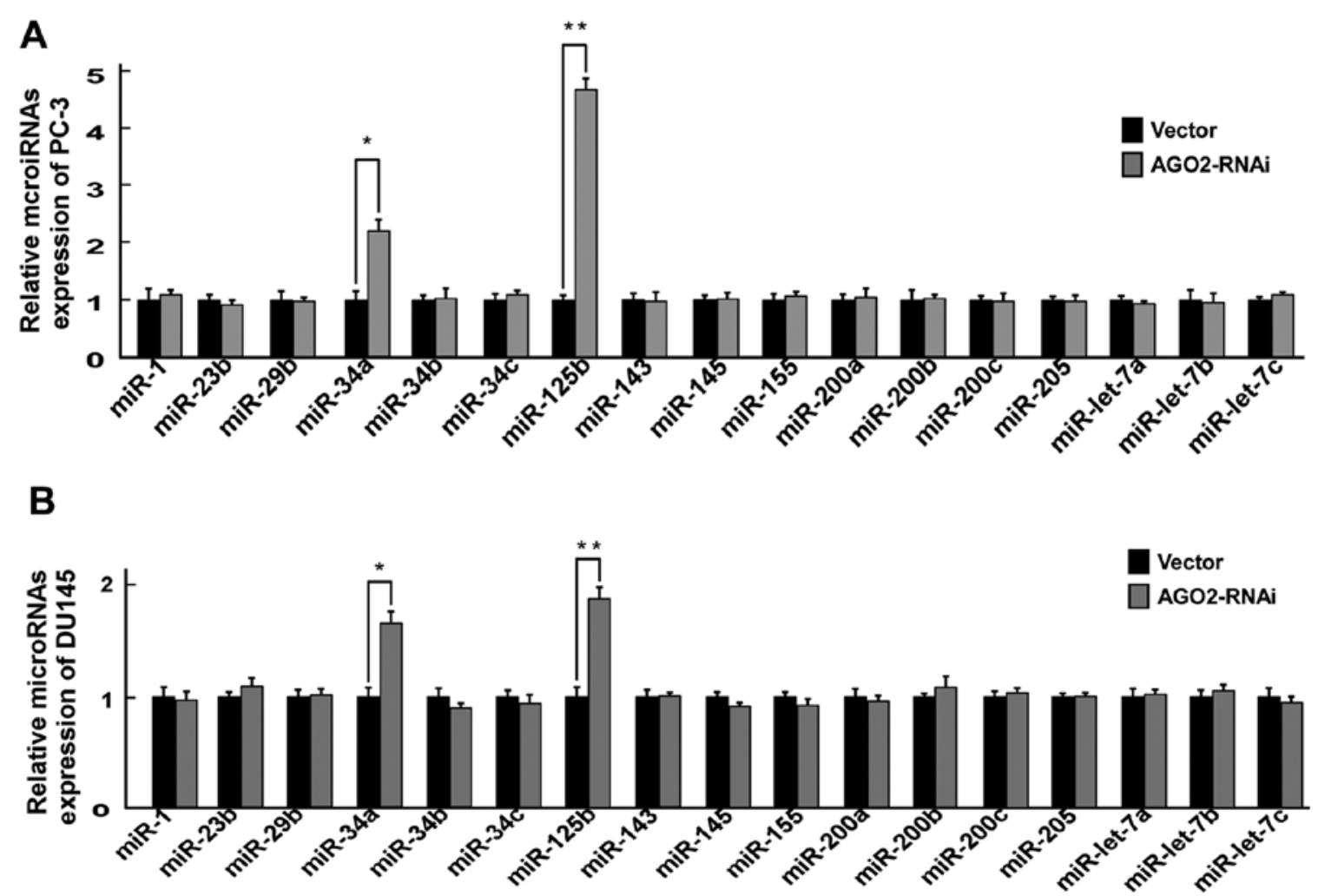

Figure 6. Downregulation of AGO2 promoted miR-125b and miR-34a expression in PCa cells $\left({ }^{*} \mathrm{p}<0.05,{ }^{* * *} \mathrm{p}<0.01\right)$.

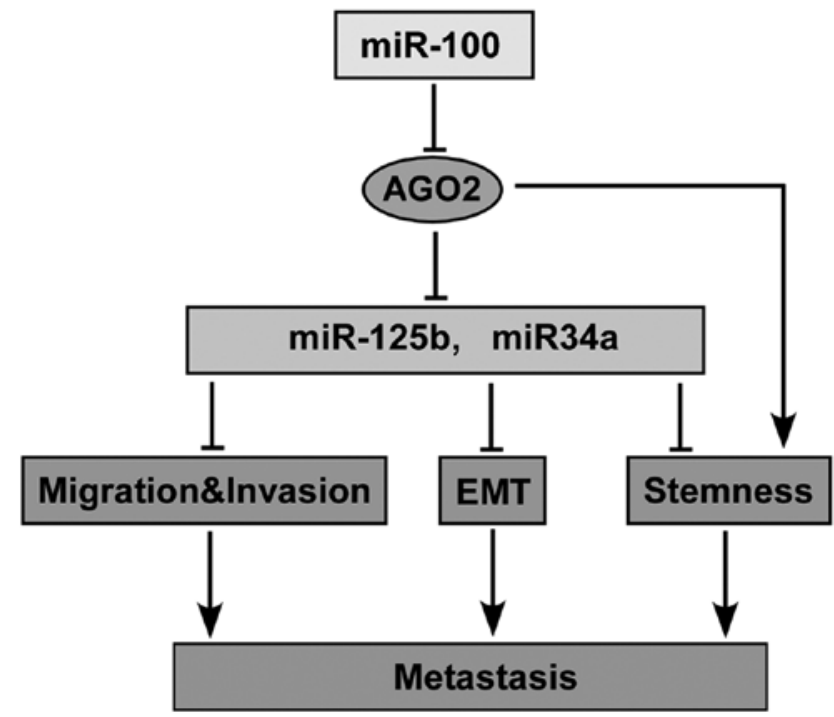

Figure 7. A diagram of the proposed interconnections among miR-100/ AGO2, migration, invasion, EMT, stemness and metastasis.

and progression of PCa metastasis $(5-9,32)$, in PC-3/AGO2RNAi, PC-3/vector, DU145/AGO2-RNAi and DU145/vector by real-time PCR, and found that downregulation of $\mathrm{AGO} 2$ significantly upregulated miR-125b and miR34a expression (Fig. 6).

\section{Discussion}

Our previous study found that miR-100 significantly decreased in bone metastasis tissue compared with primary PCa (5). In the present study, we found that the expression of miR-100 was significantly lower in PCa specimens with bone metastases than that without metastases. Leite et al $(13,14)$ also reported that miR-100 was downregulated during the PCa progression, from high grade prostate intraepithelial neoplasia through metastasis. Moreover, Sun et al (10) found that miR-100 was downregulated in the more advanced $\mathrm{PCa}$ C4-2 cells relative to the parental LNCaP cells. Importantly, our results showed that mir-100 negatively regulated migration, invasion EMT and stemness properties of PCa cells. Therefore, these findings indicate that mir-100 is a metastatic suppressor in PCa.

However, mir-100 appears to be cancer specific in regulating tumor metastasis. Huang et al (33) found that miR-100 expression increased in metastatic pancreatic cancer cells. Furthermore, Wang et al (34) reported that miR-100 overexpression strongly associates with advanced tumor progression in renal cell carcinoma. Moreover, miR-100 was transiently introduced into A549 cells, NCI-H727 and NCI-H1437 cells, resulting in a significant increase of cell migration activity (35). The above results suggest that miR-100 may be a promoter of tumor metastasis. On the contrary, in clear cell renal cell carcinomas, miR-100 was downregulated in metastatic tissue samples compared with normal tissue and was downregulated in metastatic tissue in comparison with primary tumor tissue (36). Furthermore, downregulation of miR-100 was significantly associated with lymph node metastasis and reduced survival in Small cell carcinoma of the cervix (37). Thus, these findings supported that miR-100 was a suppressor of metastasis.

Some previous studies have demonstrated that Ago2 is a promoter of metastasis in different solid tumors. In hepato- 
cellular carcinoma (HCC), Ago2 overexpression promoted migration and metastasis of HCC cells (23). AGO2 was overexpressed in colon cancer relative to adjacent non-cancer tissue and the expression of $\mathrm{AGO} 2$ appeared to increase in advanced tumors with distant metastasis, suggesting it may promote tumor invasion (38). In human breast cancer cells, high level of Ago2 was correlated with an enhanced proliferation and migration ability (39). In serous ovarian carcinoma, AGO2 mRNAs were overexpressed in solid metastases compared with primary carcinomas and higher levels of AGO2 mRNA was significantly associated with high-grade histology (40). In head and neck squamous cell carcinoma cell lines and primary tumors, AGO2 was overexpressed and was functionally significant in cell lines (41). In the present study, the results showed that downregulation of $\mathrm{AGO} 2$ repressed migration, invasion, EMT and stemness of PCa cells. These findings indicated that AGO2 was a promoter of tumor progression and metastasis. Furthermore, our results showed that $\mathrm{AGO} 2$ is a direct target of miR-100. Thus, the critical mechanism of miR-100 suppression of metastasis in PCa cells may be to downregulate AGO2 expression. However, it remains to be determined how $\mathrm{AGO} 2$ regulates metastasis.

Recent studies have shown that Ago2 directly regulates miRNA biosynthesis (24). For example, the silencing of Ago2 upregulated miR-125b expression in myeloblastic HL60 cells (42). In the present study, we showed that repressing AGO2 in PCa cells enhanced expression of miR-125b and miR-34a, which were downregulated in human PCa tissues compared with normal tissues and in bone metastatic PCa tissues compared to primary tumors $(5,7,10,12)$. Many studies have demonstrated that miR-100 and miR-125b were concurrently downregulated in human PCa tissues $(10,12)$ and in bone metastatic PCa tissue (5). These findings suggested that downregulation of miR-125b and miR-34a in human primary and metastatic PCa tissues might be related to upregulation of Ago2, which was directly regulated by miR-100.

Previous studies have demonstrated that miR-34a and miR$125 \mathrm{~b}$ are mainly metastatic suppressors, and play an important role in inhibiting metastasis of cancer cells, including PCa cells (7,12,43-48). The miR-34a was able to directly inhibit EMT regulators Snail1, ZEB1 and ZEB2 $(43,44)$, and the stemness factor CD44 in PCa cells (7). Downregulation of miR-125b was able to promote metastatic oncoprotein expression and enhance migration, invasion and metastasis (45-48). ERBB2, a target of miR-125b (49), played an important role in promoting stemness properties and EMT (50-52). Therefore, an important mechanism of $\mathrm{AGO} 2$ promoting metastasis of $\mathrm{PCa}$ cells may be to enhance metastasis-promoting proteins, EMT and stemness by repressing expression of miR-34a and miR-125b.

Recent studies have demonstrated that Ago2 can directly regulate expression of stemness factors Oct4, Sox 2, Nanog, Klf4 and c-myc following its binding to the regulatory regions of functional genes (53). Moreover, in Ago2-knockdown embryos at the blastocyst stage, transcription levels of Oct3/4, Nanog and Sox 2 were decreased (54). In this study, our results showed that downregulation of $\mathrm{AGO} 2$ repressed expression of stemness factors Oct4, Klf4 and c-myc of PCa cells. Thus another mechanism of Ago2 regulating metastasis of PCa may be to directly upregulate stemness gene expression. In addition, Ago2 might have regulatory functions in CSC self-renewal through the RNA-mediated gene silencing mechanism as a component of RISC (55).

Our results showed that $\mathrm{AGO} 2$ was a direct target of miR-100, and played an opposite role to miR-100 in regulating migration, invasion, EMT and stemness of PCa cells. Furthermore, downregulation of AGO2 was able to partially reverse the effects seen with miR-100 downregulation in PCa cells. Importantly, downregulation of AGO2 enhanced expression of miR-34a and $-125 \mathrm{~b}$ which can suppress migration, invasion, EMT and stemness of cancer cells. Thus, a proposed model of the close interconnections among miR-100, AGO2 and metastasis is shown in Fig. 7.

In conclusion, our findings indicated that miR-100 negatively regulates the metastatic ability of PCa cells at least partially by targeting AGO2 which repressed the metastatic suppressor miR-34a and miR-125b expression, and modulated migration, invasion, EMT and stemness of cancer cells. Our results suggest that miR-100/AGO2 may play an important role in regulating metastasis of $\mathrm{PCa}$ and is a potential novel target for prevention and therapy.

\section{Acknowledgements}

This study was supported by grants from the National Natural Science Foundation of China (no. 81272938).

\section{References}

1. Nelson WG, De Marzo AM and Isaacs WB: Prostate cancer. N Engl J Med 349: 366-381, 2003.

2. Nauseef JT and Henry MD: Epithelial-to-mesenchymal transition in prostate cancer: paradigm or puzzle? Nat Rev Urol 8: 428-439, 2011.

3. Zhang J and Ma L: MicroRNA control of epithelial-mesenchymal transition and metastasis. Cancer Metastasis Rev 31: 653-662, 2012.

4. Pencheva $\mathrm{N}$ and Tavazoie SF: Control of metastatic progression by microRNA regulatory networks. Nat Cell Biol 15: 546-554, 2013.

5. Peng X, Guo W, Liu T, et al: Identification of miRs-143 and -145 that is associated with bone metastasis of prostate cancer and involved in the regulation of EMT. PLoS One 6: e20341, 2011.

6. Tucci P, Agostini M, Grespi F, et al: Loss of p63 and its microRNA-205 target results in enhanced cell migration and metastasis in prostate cancer. Proc Natl Acad Sci USA 109: 15312-15317, 2012.

7. Liu C, Kelnar K, Liu B, et al: The microRNA miR-34a inhibits prostate cancer stem cells and metastasis by directly repressing CD44. Nat Med 17: 211-215, 2011.

8. Saini S, Majid S, Yamamura S and Tabatabai L: Regulatory role of mir-203 in prostate cancer progression and metastasis. Clin Cancer Res 17: 5287-5298, 2011.

9. Kong D, Li Y, Wang Z, Banerjee S, Ahmad A, Kim HR and Sarkar FH: miR-200 regulates PDGF-D-mediated epithelialmesenchymal transition, adhesion, and invasion of prostate cancer cells. Stem Cells 27: 1712-1721, 2009.

10. Sun D, Lee YS, Malhotra A, et al: miR-99 family of MicroRNAs suppresses the expression of prostate-specific antigen and prostate cancer cell proliferation. Cancer Res 71: 1313-1324, 2011.

11. Tong AW, Fulgham P, Jay C, et al: MicroRNA profile analysis of human prostate cancers. Cancer Gene Ther 16: 206-216, 2009.

12. Giangreco AA, Vaishnav A, Wagner D, Finelli A, et al: Tumor suppressor microRNAs, miR-100 and $-125 b$, are regulated by 1,25-dihydroxyvitamin D in primary prostate cells and in patient tissue. Cancer Prev Res 6: 483-494, 2013.

13. Leite KR, Sousa-Canavez JM, Reis ST, Tomiyama AH, et al: Change in expression of miR-let7c, miR-100, and miR-218 from high grade localized prostate cancer to metastasis. Urol Oncol 29: 265-269, 2011. 
14. Leite KR, Tomiyama A, Reis ST, Sousa-Canavez JM, Sañudo A, Camara-Lopes LH and Srougi M: MicroRNA expression profiles in the progression of prostate cancer-from high-grade prostate intraepithelial neoplasia to metastasis. Urol Oncol 31: 796-801, 2013.

15. Porkka KP,Pfeiffer MJ, Waltering KK, Vessella RL, Tammela TL and Visakorpi T: MicroRNA expression profiling in prostate cancer. Cancer Res 67: 6130-6135, 2007.

16. Hanahan D and Weinberg RA: Hallmarks of cancer: the next generation. Cell 144: 646-674, 2011

17. Sethi S, Macoska J, Chen W and Sarkar FH: Molecular signature of epithelial-mesenchymal transition (EMT) in human prostate cancer bone metastasis. Am J Transl Res 3: 90-99, 2010.

18. Hugo H, Ackland ML, Blick T, Lawrence MG, Clements JA Williams ED and Thompson EW: Epithelial-mesenchymal and mesenchymal-epithelial transitions in carcinoma progression. J Cell Physiol 213: 374-383, 2007.

19. Monteiro J and Fodde R: Cancer stemness and metastasis: therapeutic consequences and perspectives. Eur J Cancer 46 : $1198-1203,2010$

20. Xia $\mathrm{H}$ and Hui KM: MicroRNAs involved in regulating epithelial-mesenchymal transition and cancer stem cells as molecular targets for cancer therapeutics. Cancer Gene Ther 19 : 723-730, 2012

21. Huang S, Guo W, Tang Y, Ren D, Zou X and Peng X: miR-143 and miR-145 inhibit stem cell characteristics of PC-3 prostate cancer cells. Oncol Rep 28: 1831-1837, 2012.

22. Janas MM, Wang B, Harris AS, et al: Alternative RISC assembly: binding and repression of microRNA-mRNA duplexes by human Ago proteins. RNA 18: 2041-2055, 2012.

23. Cheng N, Li Y and Han ZG: Argonaute2 promotes tumor metastasis by way of up-regulating focal adhesion kinase expression in hepatocellular carcinoma. Hepatology 57: 1906-1918, 2013

24. Cheloufi S, Dos Santos CO, Chong MM and Hannon GJ: A dicer-independent miRNA biogenesis pathway that requires Ago catalysis. Nature 465: 584-589, 2010.

25. Zhou Y, Chen L, Barlogie B, Stephens O, et al: High-risk myeloma is associated with global elevation of miRNAs and overexpression of EIF2C2/AGO2. Proc Natl Acad Sci USA 107: 7904-7909, 2010.

26. Yoo NJ, Hur SY, Kim MS, Lee JY and Lee SH: Immunohistochemical analysis of RNA-induced silencing complex-related proteins AGO2 and TNRC6A in prostate and esophageal cancers. APMIS 118: 271-276, 2010.

27. Sand M, Skrygan M, Georgas D, et al: Expression levels of the microRNA maturing microprocessor complex component DGCR8 and the RNA-induced silencing complex (RISC) components argonaute-1, argonaute-2, PACT, TARBP1, and TARBP2 in epithelial skin cancer. Mol Carcinog 51: 916-922, 2012.

28. Naoghare PK, Tak YK, Kim MJ,Han E and Song JM: Knock-down of Argonaute 2 (AGO2) induces apoptosis in myeloid leukaemia cells and inhibits siRNA-mediated silencing of transfected oncogenes in HEK-293 cells. Basic Clin Pharmacol Toxicol 109: 274-282, 2011.

29. Shekar PC, Naim A, Sarathi DP and Kumar S: Argonaute-2-null embryonic stem cells are retarded in self-renewal and differentiation. J Biosci 36: 649-657, 2011.

30. Mo YY and Beck WT: Association of human DNA topoisomerase IIalpha with mitotic chromosomes in mammalian cells is independent of its catalytic activity. Exp Cell Res 252: 50-62, 1999.

31. Livak KJ and Schmittgen TD: Analysis of relative gene expression data using real-time quantitative PCR and the $2(\mathrm{~T})$ (-Delta Delta C) method. Methods 25: 402-408, 2001.

32. Majid S, Dar AA, Saini S, Deng G, et al: MicroRNA-23b functions as a tumor suppressor by regulating Zeb1 in bladder cancer. PLoS One 8: e67686, 2013.

33. Huang J, Egger M, Grizzle W and McNally L: MicroRNA-100 regulates IGF1-receptor expression in metastatic pancreatic cancer cells. Biotech Histochem 88: 397-402, 2013.

34. Wang G, Chen L, Meng J, Chen M, Zhuang L and Zhang L: Overexpression of microRNA-100 predicts an unfavorable prognosis in renal cell carcinoma. Int Urol Nephrol 45: 373-379, 2013.
35. Shimamura T, Imoto S, Shimada Y, et al: A novel network profiling analysis reveals system changes in epithelial-mesenchymal transition. PLoS One 6: e20804, 2011.

36. Wotschofsky Z, Liep J, Meyer HA, Jung M, et al: Identification of metastamirs as metastasis-associated microRNAs in clear cell renal cell carcinomas. Int J Biol Sci 8: 1363-1374, 2012.

37. Huang L, Lin JX, Yu YH, Zhang MY, Wang HY and Zheng M Downregulation of six microRNAs is associated with advanced stage, lymph node metastasis and poor prognosis in small cell carcinoma of the cervix. PLoS One 7: e33762, 2012.

38. Li L, Yu C, Gao H and Li Y: Argonaute proteins: potential biomarkers for human colon cancer. BMC Cancer 10: 38, 2010

39. Adams BD, Claffey KP and White BA: Argonaute-2 expression is regulated by epidermal growth factor receptor and mitogenactivated protein kinase signaling and correlates with a transformed phenotype in breast cancer cells. Endocrinology 150: $14-23,2009$

40. Vaksman O, Hetland TE, Trope' CG, Reich R and Davidson B: Argonaute, Dicer, and Drosha are up-regulated along tumor progression in serous ovarian carcinoma. Hum Pathol 43 2062-2069, 2012

41. Chang SS, Smith I, Glazer C, Hennessey P and Califano JA: EIF2C is overexpressed and amplified in head and neck squamous cell carcinoma. ORL J Otorhinolaryngol Relat Spec 72: 337-343, 2010.

42. Iosue I, Quaranta R, Masciarelli S, et al: Argonaute 2 sustains the gene expression program driving human monocytic differentiation of acute myeloid leukemia cells. Cell Death Dis 4: e926, 2013.

43. Siemens H, Jackstadt R, Hünten S, Kaller M, Menssen A, Götz U and Hermeking $\mathrm{H}$ : miR-34 and SNAIL form a double-negative feedback loop to regulate epithelial-mesenchymal transitions. Cell Cycle 10: 4256-4271, 2011.

44. Kim T, Veronese A, Pichiorri F, Lee TJ, et al: p53 regulates epithelial-mesenchymal transition through microRNAs targeting ZEB1 and ZEB2. J Exp Med 208: 875-883, 2011.

45. Ferracin M, Bassi C, Pedriali M, et al: miR-125b targets erythropoietin and its receptor and their expression correlates with metastatic potential and ERBB2/HER2 expression. Mol Cancer 12: 130,2013

46. Li Y, Chao Y, Fang Y, et al: MTA1 promotes the invasion and migration of non-small cell lung cancer cells by downregulating miR-125b. J Exp Clin Cancer Res 32: 33, 2013.

47. Rajabi H, Joshi MD, Jin C, Ahmad R and Kufe D: Androgen receptor regulates expression of the MUC1-C oncoprotein in human prostate cancer cells. Prostate 71: 1299-1308, 2011.

48. Liang L, Wong CM, Ying Q, et al: MicroRNA-125b suppressesed human liver cancer cell proliferation and metastasis by directly targeting oncogene LIN28B2. Hepatology 52: 1731-1740, 2010.

49. Scott GK, Goga A, Bhaumik D, Berger CE, Sullivan CS and Benz CC: Coordinate suppression of ERBB2 and ERBB3 by enforced expression of microRNA miR-125a or miR-125b. J Biol Chem 282: 1479-1486, 2007.

50. Nair R, Roden DL, Teo WS, et al: c-Myc and Her2 cooperate to drive a stem-like phenotype with poor prognosis in breast cancer. Oncogene: Sep 23, 2013 (Epub ahead of print). doi: 10.1038/ onc. 2013.368 .

51. Cheng JC, Qiu X, Chang HM and Leung PC: HER2 mediates epidermal growth factor-induced down-regulation of E-cadherin in human ovarian cancer cells. Biochem Biophys Res Commun 434: 81-86, 2013

52. Kim IY, Yong HY, Kang KW and Moon A: Overexpression of ErbB2 induces invasion of MCF10A human breast epithelial cells via MMP-9. Cancer Lett 275: 227-233, 2009.

53. Kim BS, Im YB, Jung SJ, Park CH and Kang SK: Argonaute2 regulation for $\mathrm{K}^{+}$channel-mediated human adipose tissuederived stromal cells self-renewal and survival in nucleus. Stem Cells Dev 21: 1736-1748, 2012.

54. Shen XH, Han YJ, Cui XS and Kim NH: Ago2 and GW182 expression in mouse preimplantation embryos: a link between microRNA biogenesis and GW182 protein synthesis. Reprod Fertil Dev 22: 634-643, 2010.

55. Carmell MA, Xuan Z, Zhang MQ and Hannon GJ: The Argonaute family: tentacles that reach into RNAi, developmental control, stem cell maintenance, and tumorigenesis. Genes Dev 16: $2733-2742,2002$ 